\title{
Wide-Field-of-View Longwave Camera for the Characterization of the Earth's Outgoing Longwave Radiation
}

\author{
Luca Schifano $^{1,2, * \mathbb{C}}$, Lien Smeesters ${ }^{1,3}$, Francis Berghmans ${ }^{1,3}$ and Steven Dewitte ${ }^{2}$ \\ 1 Brussels Photonics (B-PHOT), Applied Physics and Photonics Department, Vrije Universiteit Brussel, \\ Pleinlaan 2, 1050 Brussels, Belgium; lsmeeste@b-phot.org (L.S.); francis.berghmans@vub.be (F.B.) \\ 2 Royal Meteorological Institute of Belgium, Avenue Circulaire 3, 1180 Brussels, Belgium; \\ steven.dewitte@meteo.be \\ 3 Flanders Make, Pleinlaan 2, 1050 Brussels, Belgium \\ * Correspondence: luca.schifano@meteo.be
}

check for updates

Citation: Schifano, L.; Smeesters, L.; Berghmans, F.; Dewitte, S.

Wide-Field-of-View Longwave Camera for the Characterization of the Earth's Outgoing Longwave Radiation. Sensors 2021, 21, 4444. https://doi.org/10.3390/s21134444

Academic Editor: Jesper Skottfelt

Received: 27 May 2021

Accepted: 23 June 2021

Published: 29 June 2021

Publisher's Note: MDPI stays neutral with regard to jurisdictional claims in published maps and institutional affiliations.

Copyright: (c) 2021 by the authors. Licensee MDPI, Basel, Switzerland. This article is an open access article distributed under the terms and conditions of the Creative Commons Attribution (CC BY) license (https:// creativecommons.org/licenses/by/ $4.0 /)$.

\begin{abstract}
The measurement of the Earth's Outgoing Longwave Radiation plays a key role in climate change monitoring. This measurement requires a compact wide-field-of-view camera, covering the 8-14 $\mu \mathrm{m}$ wavelength range, which is not commercially available. Therefore, we present a novel thermal wide-field-of-view camera optimized for space applications, featuring a field of view of $140^{\circ}$ to image the Earth from limb to limb, while enabling a high spatial resolution of $4.455 \mathrm{~km}$ at nadir. Our cost-effective design comprises three germanium lenses, of which only one has a single aspherical surface. It delivers a very good image quality, as shown by the nearly-diffraction-limited performance. Radiative transfer simulations indicate excellent performance of our camera design, enabling an estimate of the broadband Outgoing Longwave Radiation with a random relative error of $4.8 \%$.
\end{abstract}

Keywords: Earth Radiation Budget; Earth Energy Imbalance; Outgoing Longwave Radiation; wide field of view; space instrumentation; radiative transfer simulations; aspherical optical design; refractive imaging system

\section{Introduction}

In our pursuit to better understand Earth's changing climate, the monitoring of the Earth's radiation budget (ERB) is of major importance [1]. This budget quantifies the radiative energy fluxes at the top-of-atmosphere (TOA), which can best be monitored from space. The state-of-the-art ERB measurements have been provided so far by NASA's Clouds and the Earth's Radiant Energy System (CERES) program [2,3]. They feature a spatial resolution equal to $20 \mathrm{~km}$ at nadir for the CERES instrument on-board of the Terra and Aqua satellites, and $10 \mathrm{~km}$ for the CERES instrument on-board of the Tropical Rainfall Measuring Mission (TRMM). The latter, as a precessing satellite, samples all solar illumination configurations, which makes it well suited for the development of Angular Distribution Models (ADM) [4]. As the field of view (FOV) of CERES is narrow $\left(1.3^{\circ} \times 2.6^{\circ}\right)$, the full viewing angle coverage is obtained by the CERES rotating azimuth scan capability. Scene identification is provided by a multispectral imager, the MODIS imager, flying on the same satellites as the CERES instrument, e.g., on the Terra and Aqua satellites [5].

To improve this monitoring, we propose a novel space mission, with a payload that combines several wide-field-of-view (WFOV) instruments, which allow observing the Earth from limb to limb. With this WFOV, no scanning elements are required, which eases the mechanical integration. In addition, our design fits within $4 \mathrm{dm}^{3}$ units of a CubeSat, forming a compact and relatively low-cost payload, suitable for integration on nano- or micro-satellites. Such small satellites can be used to supplement CERES and its follow-on mission Libera-the space mission recently selected in the framework of the Earth Venture Continuity [6,7] - e.g., for improving the sampling of the diurnal cycle. In this context, our 
design is particularly relevant since currently no follow-on mission for the sampling of the ERB from the morning orbit is foreseen after the end of life of the CERES instrument on the Terra satellite, which is expected around 2026.

The first instrument of our payload is a WFOV radiometer [8] that aims to measure the total radiation emitted by both the Sun and the Earth, with an estimated accuracy of $0.44 \mathrm{~W} / \mathrm{m}^{2}$. The ability to measure those quantities with the same instrument decreases the calibration errors, and leads to an accurate measurement of the Earth's Energy Imbalance (EEI), which is the key parameter that drives the current climate change [9-11]. Combining this radiometer with WFOV cameras allows increasing the spatial resolution and enables identifying scenes. In addition, the use of cameras operating in different wavelengths regions allows distinguishing between the Reflected Solar Radiation (RSR), measured by a shortwave (SW, [400-1100] nm) camera [12], and the Outgoing Longwave Radiation (OLR), measured by a longwave (LW, [8-14] $\mu \mathrm{m})$ camera.

This paper deals with the WFOV LW camera that aims to characterize the OLR with a maximum relative error of $5 \%$, and where we target the optical design to achieve a nadir spatial resolution of minimally $5 \mathrm{~km}$. To the best of our knowledge, there is no commercial off-the-shelf (COTS) compact camera that operates in the [8-14] $\mu \mathrm{m}$ wavelength range and that features a FOV of $140^{\circ}$ for the characterization of the OLR. State-of-the-art thermal cameras include either imaging designs operating in this wavelength range but with a smaller FOV $\left(51^{\circ} \times 40^{\circ}\right)$ [13], or cameras with the required FOV but in another and smaller wavelength range ([14-16] $\mu \mathrm{m})[14]$, or systems that both operate in a different wavelength range and feature a smaller FOV, e.g., in [15]. Considering the required wavelength range, the maximal FOV that is currently published is obtained with a catadioptric objective and equals to $125^{\circ} \times 96^{\circ}$ [16], which is still significantly smaller than our targeted value of $140^{\circ}$ (circular full FOV).

Our manuscript is structured as follows: the first part (Section 2) is dedicated to the optical system design of the LW camera, while the second part (Section 3) is devoted to the estimate of the broadband OLR using this LW camera. The latter also reports on its performance based on radiative transfer simulations. Section 4 discusses our results as well as prospects for future work, and Section 5 closes this paper with a summary.

\section{Optical System Design}

This section focuses on the optical system design of the LW camera. Section 2.1 discusses the technical requirements and constraints that drive the optical design, while Section 2.2 presents the optical camera system, as well as an evaluation of the image quality, based on spot sizes, contrast and aberrations.

\subsection{Scientific and Technical Requirements}

The optical system design must account for the following set of requirements.

(1) The Earth should be seen from limb to limb, from a nominal satellite altitude of $700 \mathrm{~km}$.

(2) The camera should enable scene identification.

(3) The camera should measure LW radiation, allowing to reconstruct the OLR on a stand-alone basis with an error of maximally $5 \%$, as stated in [8].

(4) At nadir, the camera should have a resolution of $5 \mathrm{~km}$ or better.

(5) The volume of the camera (optics and detector) should fit within 1 CubseSat Unit (1U).

(6) The optical system should be designed with a minimal amount of optical elements and optical materials, in order to limit the cost and ease the fabrication.

To observe the Earth from limb to limb from an altitude of $700 \mathrm{~km}$, the full FOV should be minimally $127^{\circ}=2 \times 63.5^{\circ}$. Taking a margin for the altitude and pointing errors into account, we target a slightly larger FOV, of the order of $2 \times 70^{\circ}$. This margin also allows for some additional design freedom and enables reducing the aberrations and/or relaxing the tolerances in the final design stage, by reverting to a slightly smaller FOV. Regarding the detector, we favor the use of a COTS uncooled microbolomoter array that is sensitive in the 
range from 8 to $14 \mu \mathrm{m}$. We selected the ULIS/Lynred Pico1024Gen2 detector, comprising $1024 \times 768$ pixels, with a pixel pitch of $17 \mu \mathrm{m}$. To image the Earth from limb to limb, we use a circular area on the detector with a radius of $6.528 \mathrm{~mm}$.

\subsection{Optical Design of the LW Camera}

The optical design of the longwave camera is refractive and makes use of three germanium lenses (Figure 1). The back surface of the second lens is an asphere described up to the 8th order aspheric term. Germanium lenses can be found in the SCHOTT ${ }^{\circledR}$ catalog [17] and are suited for space applications. They have a high refractive index (4.0 between 8 and $14 \mu \mathrm{m}$ ), allowing us to bend the incoming rays efficiently with a minimum number of optical elements (Table 1). Note that the amount of elements is intentionally limited to reduce the cost of the optical design and to fit the full system within $1 \mathrm{U}$. The stop aperture has a diameter of $21 \mathrm{~mm}$ and is placed just before the second lens, such that each field fills the full aperture. Also, the High-Yield manufacturing-feature of Zemax OpticStudio ${ }^{\circledR}$ [18] has been used to improve the manufacturing feasibility of our design. To optimize our optical system, we start with the spot size as our merit function. Once the design is near-diffraction-limited, we further evaluate the image quality by considering the Modulation Transfer Function (MTF). Our optical design (Figure 1) is obtained after iterative optimization of the lens parameters, yielding an optimized performance, while taking the above requirements and constraints into account.

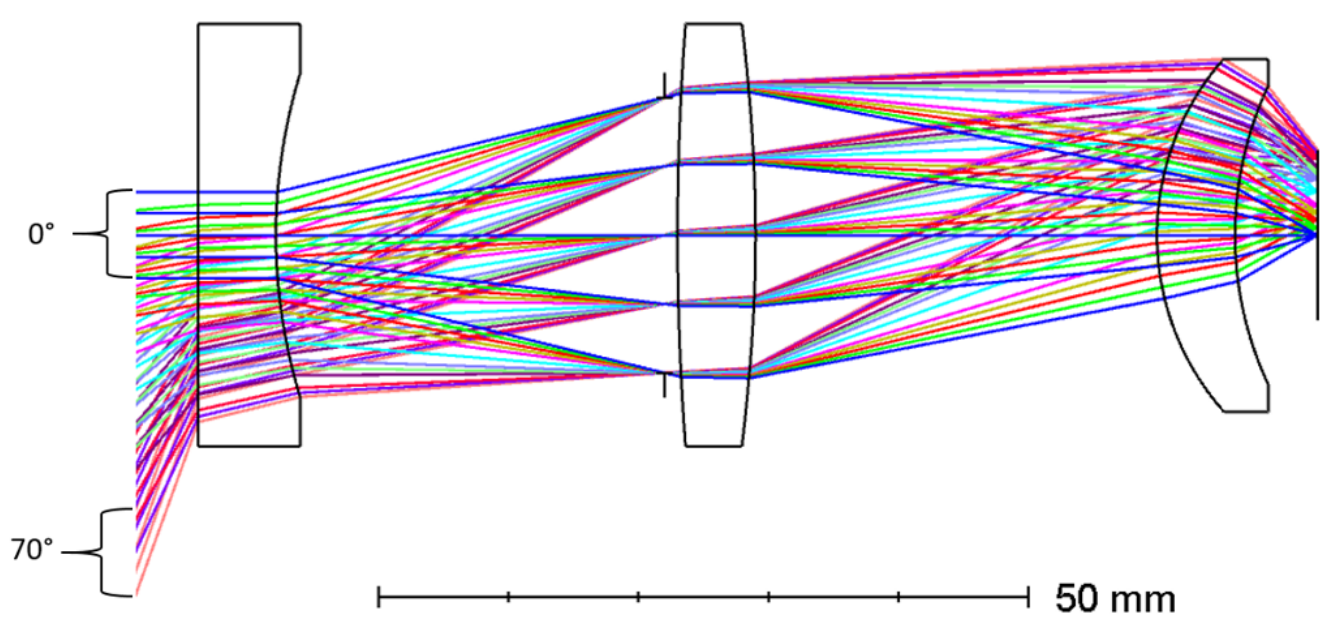

Field $\left({ }^{\circ}\right)$

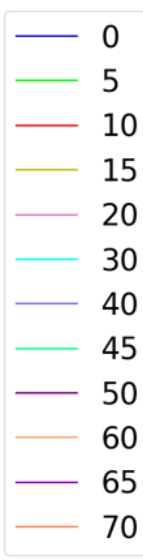

Figure 1. Optical design of the LW camera. The total axial length equals $86.12 \mathrm{~mm}$. The system consists of 3 singlet lenses. The aperture stop is situated between the first two lenses. The circular image on the detector has a radius of $6.528 \mathrm{~mm}$. The different colors correspond to the different fields between $0^{\circ}$ and $70^{\circ}$.

Table 1. Lens data: surface types, materials, thicknesses and diameters. The 3 lenses are made of Ge.

\begin{tabular}{cccccc}
\hline & Front Surface Type & Back Surface Type & Material & Thickness & Diameter \\
\hline 1st lens & Spherical & Spherical & Ge & $4 \mathrm{~mm}$ & $32.4 \mathrm{~mm}$ \\
2nd lens & Spherical & Aspherical & Ge & $6 \mathrm{~mm}$ & $32.4 \mathrm{~mm}$ \\
3rd lens & Spherical & Spherical & Ge & $6 \mathrm{~mm}$ & $27 \mathrm{~mm}$ \\
\hline
\end{tabular}

The full FOV is circular and equals $140^{\circ}$ (Figure 1), which is sufficient to cover the Earth from limb to limb while foreseeing a margin for pointing errors. To evaluate the performance of the camera system, we consider the spot diagrams shown in Figure 2. The spot size is simulated for different fields between $0^{\circ}$ and $70^{\circ}$, corresponding to the fields presented in Figure 1. In Figure 2, the black circles correspond to the Airy disks and the different colors represent the different wavelengths. When optimizing the optical design, 

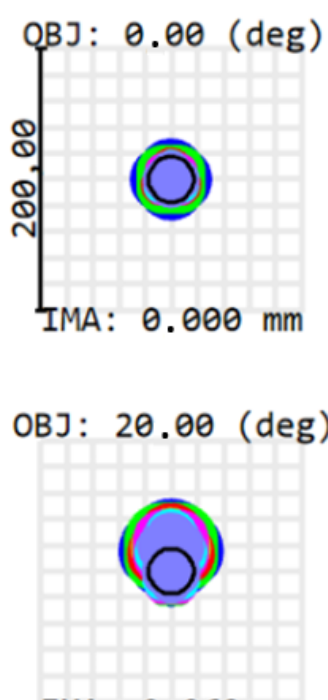

IMA: $2.263 \mathrm{~mm}$

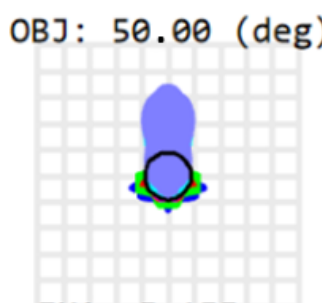

IMA: $5.155 \mathrm{~mm}$ the aim is to match the RMS spot size with the Airy disk, to obtain a near-diffraction-limited optical design, where the Airy disk is calculated with the Nyquist criterion.

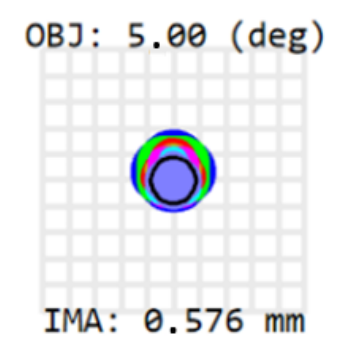

OBJ : $30.00(\mathrm{deg})$

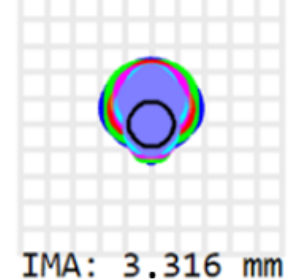

IMA: $3.316 \mathrm{~mm}$

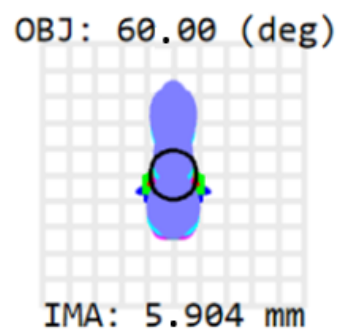

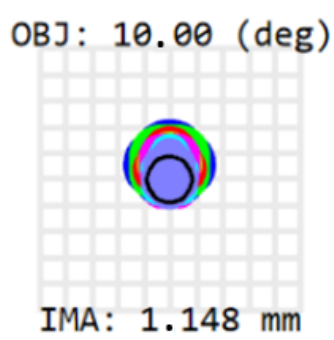

OBJ : $40.00(\mathrm{deg})$
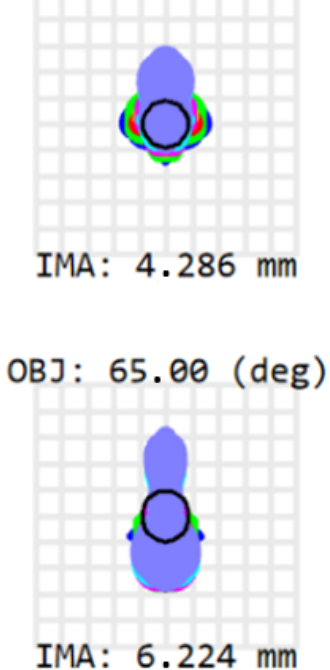
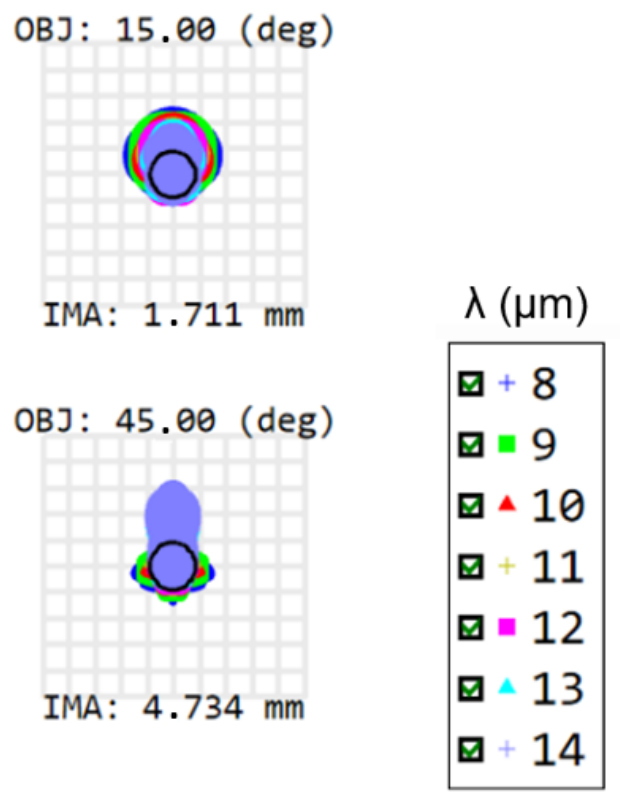

Figure 2. Spot sizes for fields between $0^{\circ}$ and $70^{\circ}$, for all wavelengths between 8 and $14 \mu \mathrm{m}$ (as visualized by the different colors in each spot plot). The Airy disk radii (black circles) equal $17.28 \mu \mathrm{m}$. Based on the spots, the system shows a good image quality. OBJ (in degrees) defines the object field and IMA (in mm) defines the image height of the centroid on the detector. This figure indicates that the best performance is obtained on-axis, while off-axis spots show less favorable performance.

The main design challenge is the wide full FOV of $140^{\circ}$. In addition to the fact that this imposes a major challenge to correct the aberration at all fields, a low f-number (ratio $f / D$ ) of 1.0 is required to match the Airy disk size with the pixel size. Nevertheless, it can be managed using a single aspheric surface (Table 1). As can be seen in (Table 2), the obtained spot sizes are close to the Airy disk sizes, for all fields and wavelengths.

Table 2. RMS spot sizes for all fields, considering the superposition of all wavelengths.

\begin{tabular}{cccc}
\hline & Half FOV $\left(^{\circ}\right)$ & RMS Spot Size $(\mu \mathrm{m})$ & Airy Disk $(=\mathbf{1 7 . 2 8} \boldsymbol{\mu m})$ \\
\hline 1st field & 0 & 9.95 & diffraction-limited \\
2nd field & 5 & 10.55 & diffraction-limited \\
3rd field & 10 & 12.06 & diffraction-limited \\
4th field & 15 & 13.88 & diffraction-limited \\
5th field & 20 & 15.48 & diffraction-limited \\
6th field & 30 & 16.68 & diffraction-limited \\
7th field & 40 & 15.19 & diffraction-limited \\
8th field & 45 & 14.32 & diffraction-limited \\
9th field & 50 & 13.91 & diffraction-limited \\
10th field & 60 & 13.83 & diffraction-limited \\
\hline
\end{tabular}


Table 2. Cont.

\begin{tabular}{cccc}
\hline & Half FOV $\left({ }^{\circ}\right)$ & RMS Spot Size $(\boldsymbol{\mu m})$ & Airy Disk $(=\mathbf{1 7 . 2 8} \boldsymbol{\mu m})$ \\
\hline 11th field & 65 & 13.76 & diffraction-limited \\
12th field & 70 & 14.52 & diffraction-limited \\
\hline
\end{tabular}

To better understand the contributions for each aberration present in the spot diagram (Figure 2), we can have a look at the Seidel diagram (Figures 3 and 4), which quantifies the common aberrations in the optical system (spherical, coma, astigmatism, field curvature, distortion, axial color, lateral color) [19]. Distortion generally increases with the field, and therefore it is a common aberration in WFOV imaging systems. The front surface of the first lens contributes the most to distortion. However, there is no particular requirement on this aberration since it can be measured during pre-flight characterization and can be taken into account during the in-flight processing. When considering all aberrations except distortion, positive aberrations of one lens surface are compensated by negative aberrations of another lens, minimizing the total aberrations at the detector (Figure 3). Consequently, barrel distortion remains the main aberration at the detector (Figure 4). A quantitative view on the barrel distortion is given in Figure 5, showing that distortion is maximal at $70^{\circ}$, where it equals $18.85 \%$.

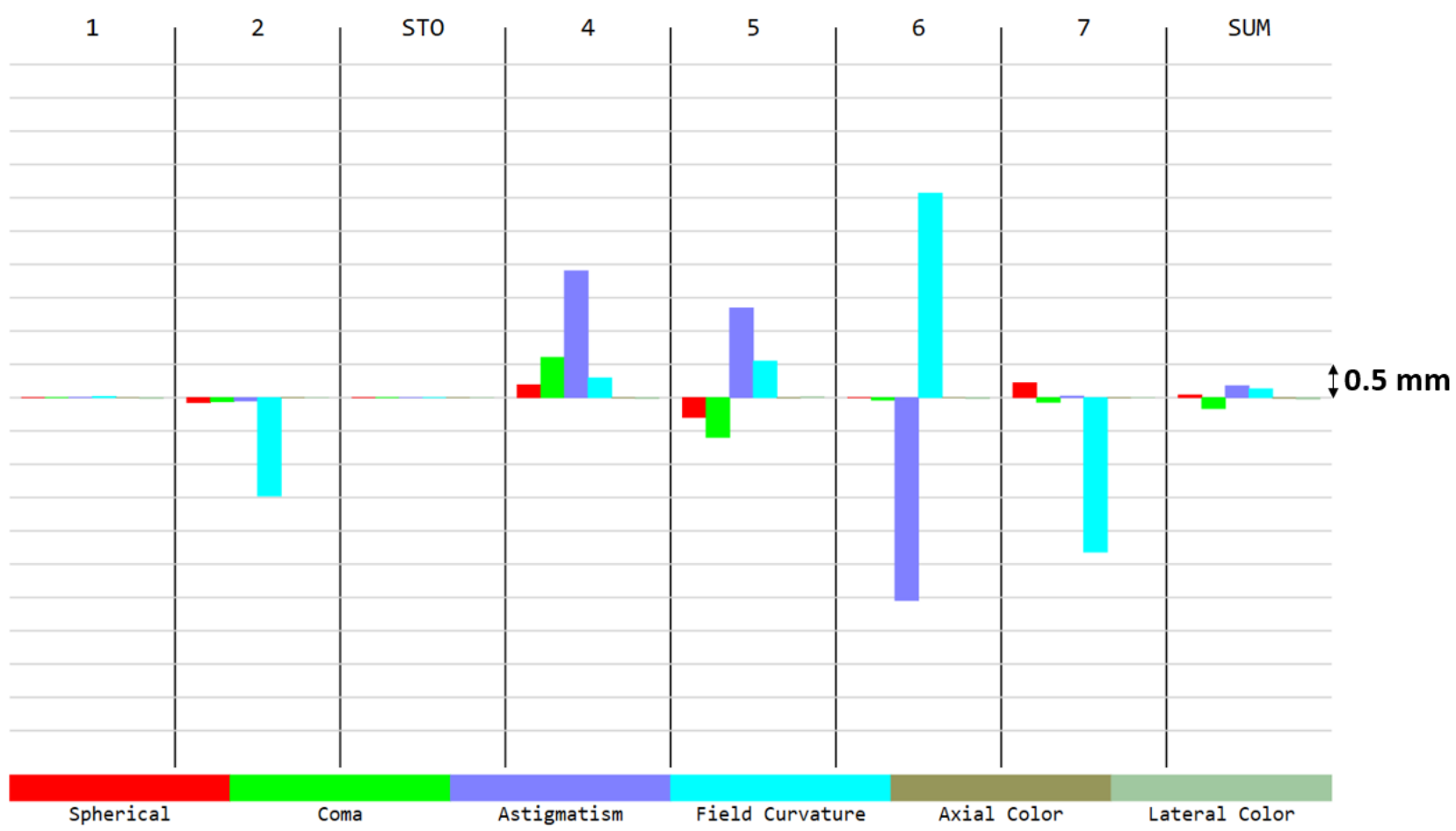

Figure 3. Seidel aberrations and (axial and lateral) chromatic aberrations, except for distortion. The aberrations are given for each surface involved in the optical system ( 1 and 2 for the first lens, $3=$ STO i.e., the stop aperture, 4 and 5 for the second lens, 6 and 7 for the third lens). The SUM represents the sum of these aberrations at the image plane. All these aberrations are corrected. The same aberration contributions were observed for all wavelengths between 8 and $14 \mu \mathrm{m}$. 


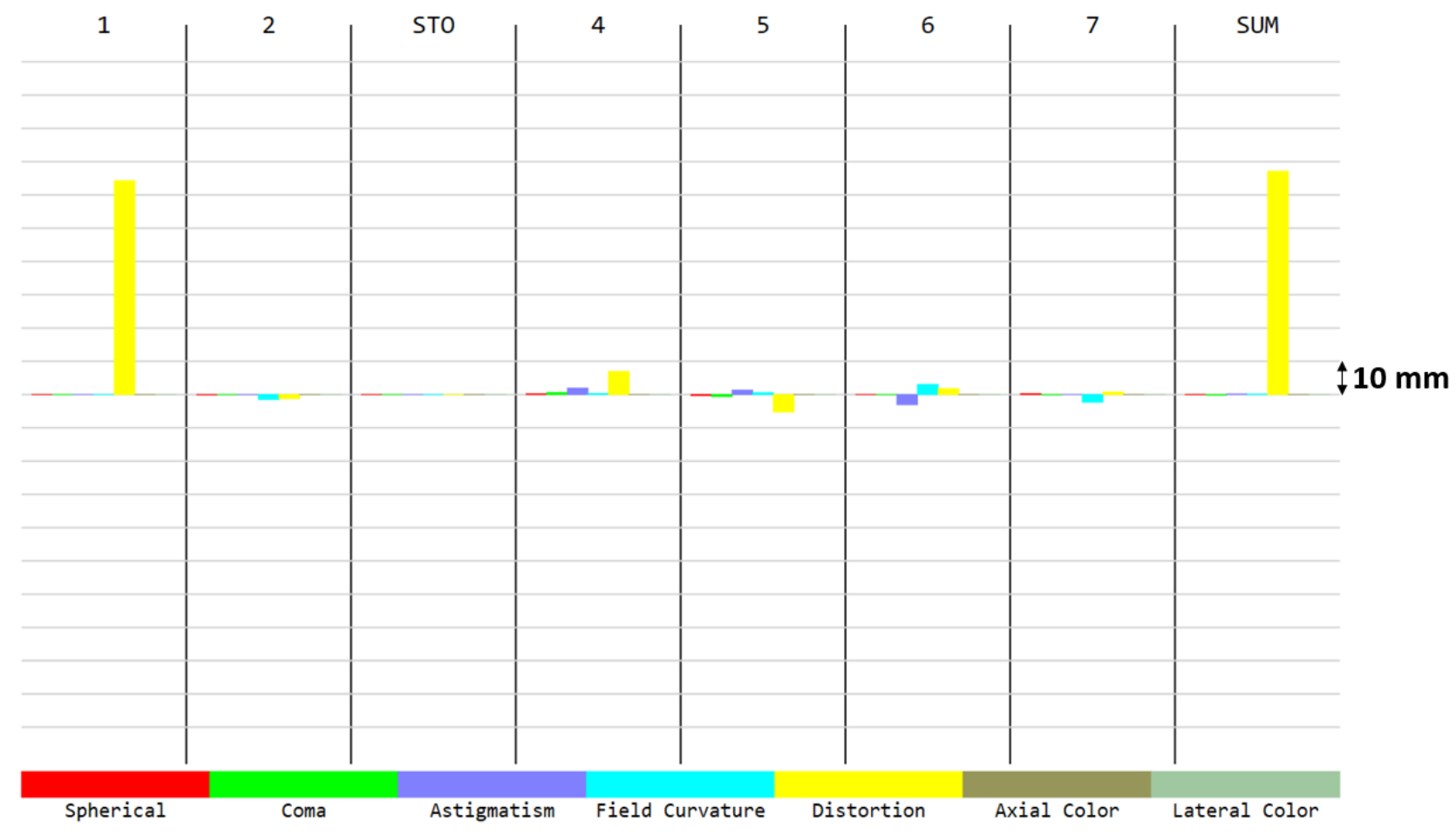

Figure 4. Five Seidel aberrations and (axial and lateral) chromatic aberrations. The aberrations are given for each surface involved in the optical system ( 1 and 2 for the first lens, 3 =STO i.e., the stop aperture, 4 and 5 for the second lens, 6 and 7 for the third lens). The SUM represents the sum of these aberrations at the image plane. The main aberration is the barrel distortion, mainly induced by Surface 1, i.e., the front surface of the first lens. The barrel distortion is further detailed in Figure 5. The same aberration contributions were observed for all wavelengths between 8 and $14 \mu \mathrm{m}$.

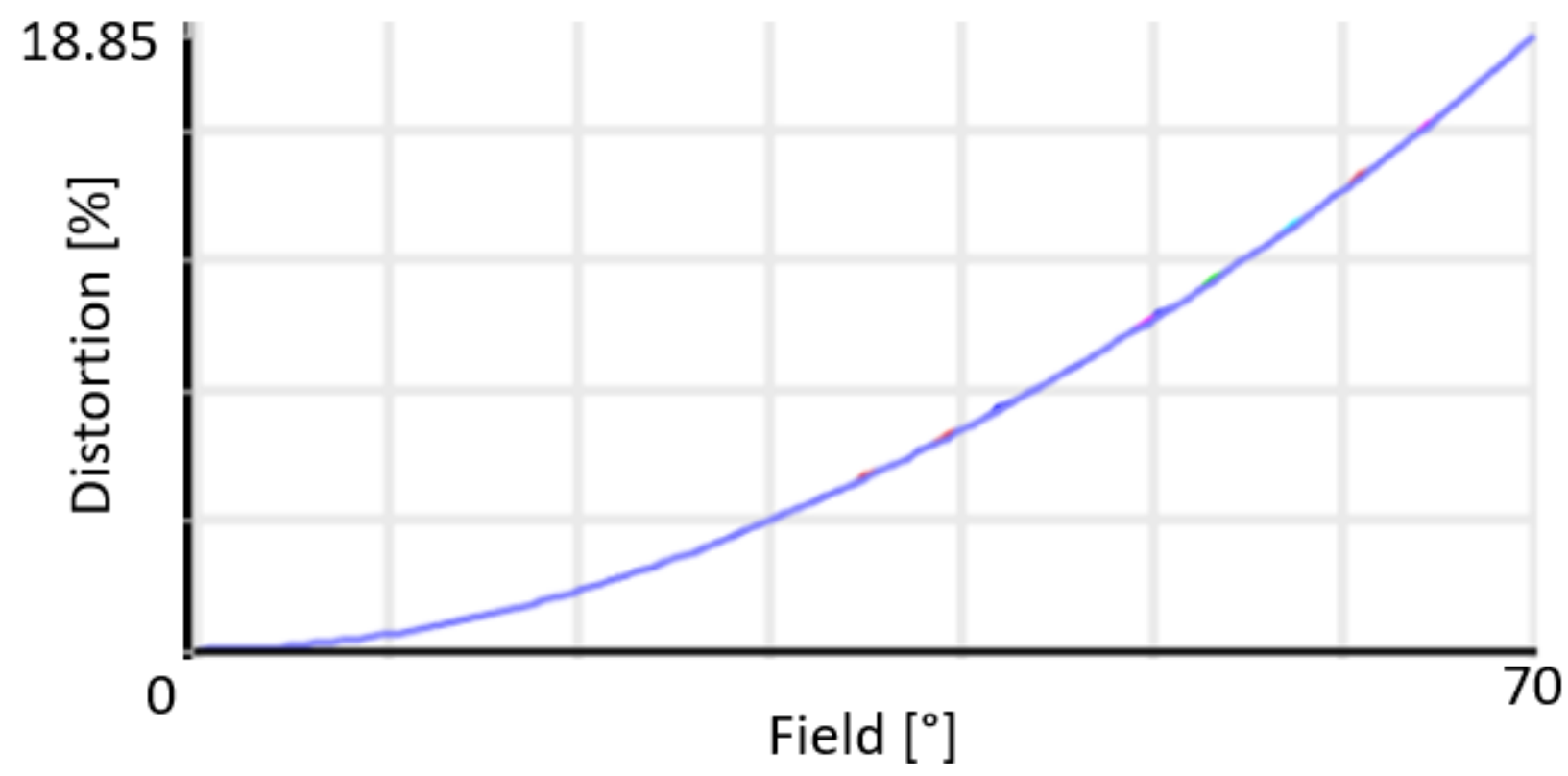

Figure 5. Barrel distortion is the main aberration present in the optical design, due to the wide field of view. Distortion is maximal at $70^{\circ}$, where it equals $18.85 \%$. In this graph, the vertical axis expresses the distortion in $\%$, and the horizontal axis gives the half FOV in degrees.

The image quality is subsequently evaluated by simulation of the MTF, which quantifies the spatial constrast. It results in a polychromatic (between 8 and $14 \mu \mathrm{m}$ ) diffraction MTF $\geq 0.5$ at 15 cycles $/ \mathrm{mm}$ (Figure 6). Considering a pixel pitch of $17 \mu \mathrm{m}$, this MTF 
indicates a good performance, satisfying the Nyquist criterion, avoiding undersampling of the image spatial variability and exaggerated blurring of the image.
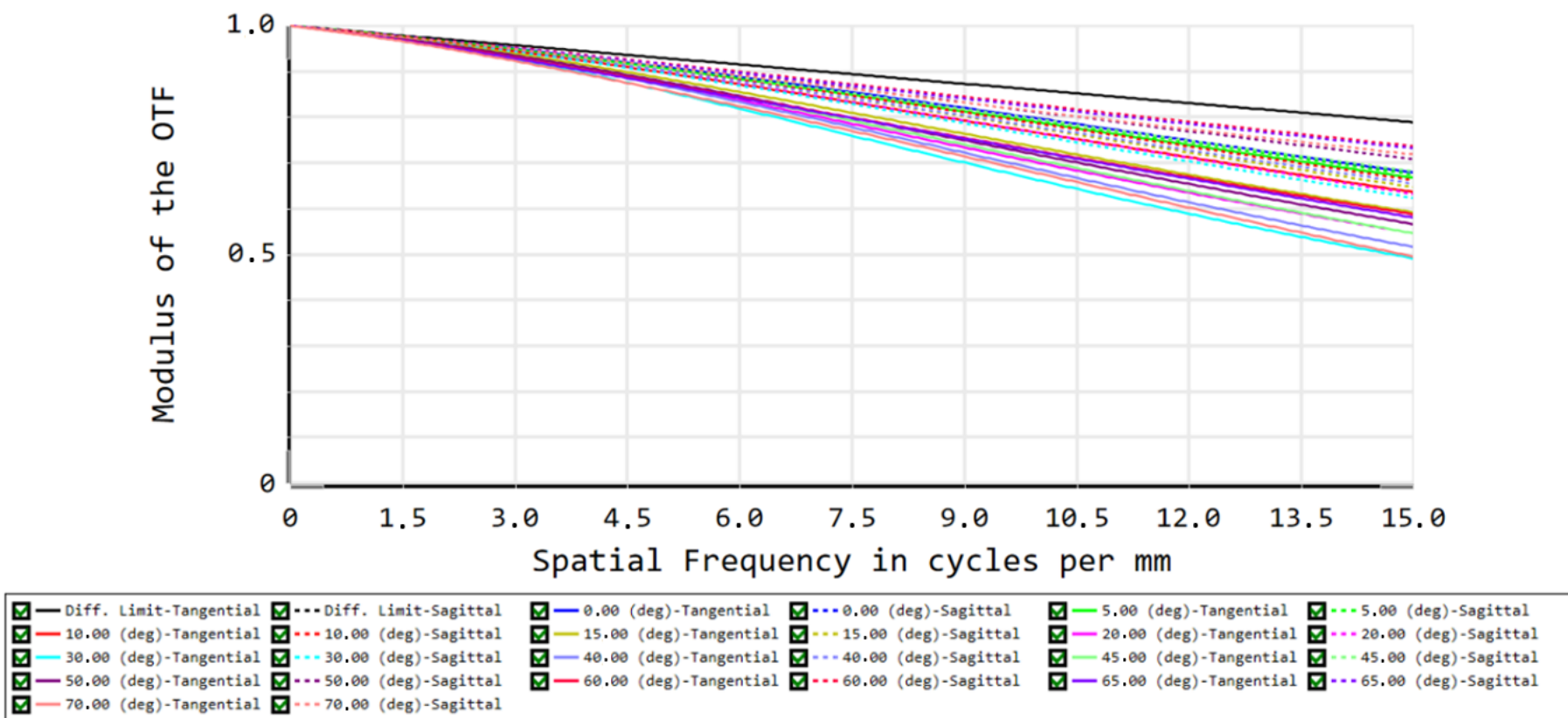

Figure 6. MTF $\geq 0.5$ at 15 cycles $/ \mathrm{mm}$. The top black line corresponds to the diffraction limit, and the colors correspond to the different fields, similar to those in Figure 1. Full lines and dashed lines correspond to tangential and sagittal planes, respectively.

\section{Remote Sensing of the Outgoing Longwave Radiation}

This section focuses on the estimate of the OLR by our developed longwave camera, and describes both the methods and results. Our camera operates between 8 and $14 \mu \mathrm{m}$, which is a narrow range of wavelengths compared to the spectral bandwidth of the OLR that ranges from 3 to $100 \mu \mathrm{m}$. The goal of our simulations is to estimate this broadband radiation (the OLR), described by what we call a broadband temperature, with a narrowband radiation (our estimation of the OLR using our LW camera) described by a narrowband temperature. The relations between the quantities pertaining to the radiation and the temperature are obtained by applying Planck's radiation law and Stefan-Boltzmann's law (cf. below). To this end, we perform radiative transfer simulations in libRadtran [20], in which different atmospheric conditions can be defined (atmospheric temperature and gas profiles, aerosols, clouds, surface properties). For this study, we choose the widely-used six clear-sky standard atmospheres from Anderson et al. [21]: U.S. Standard, Tropical, Midlatitude Summer, Midlatitude Winter, Subarctic Summer, and Subarctic Winter. For some of these standard atmospheres (U.S. Standard, Midlatitude Winter, and Subarctic Summer), we define the clouds in three different cases: water clouds, thin ice clouds, and thick ice clouds. This leads to a total of 15 different scenes, that are summarized in Table 3. The simulated data is subsequently used to assess the performance of our LW camera.

Table 3. Abbreviations for 15 different scenes, simulated in libRadtran.

\begin{tabular}{cc}
\hline Name & Abbreviation \\
\hline U.S. Standard & us \\
Tropical & $\mathrm{tr}$ \\
Midlatitude Summer & $\mathrm{ms}$ \\
Midlatitude Winter & $\mathrm{mw}$ \\
Subarctic Summer & $\mathrm{ss}$ \\
Subarctic Winter & $\mathrm{sw}$ \\
\hline
\end{tabular}


Table 3. Cont.

\begin{tabular}{cc}
\hline Name & Abbreviation \\
\hline U.S. Standard with water clouds & us_wc \\
U.S. Standard with thin ice clouds & us_ic_thin \\
U.S. Standard with thick ice clouds & us_ic_thick \\
Midlatitude Winter with water clouds & mw_wc \\
Midlatitude Winter with thin ice clouds & mw_ic_thin \\
Midlatitude Winter with thick ice clouds & mw_ic_thick \\
Subarctic Summer with water clouds & ss_wc \\
Subarctic Summer with thin ice clouds & ss_ic_thin \\
Subarctic Summer with thick ice clouds & ss_ic_thick \\
\hline
\end{tabular}

The OLR is estimated for each scene using the following approach (Figure 7):

- Simulations of the spectral brightness temperatures, in libRadtran;

- Computation of the spectral irradiances;

- Computation of the broadband temperature;

- Computation of the narrowband temperature;

- Fit of the broadband temperature as function of the narrowband temperature;

- Estimation of the OLR and calculation of the error on the OLR.

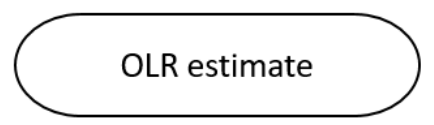

Spectral brightness temperatures (Figure 7)

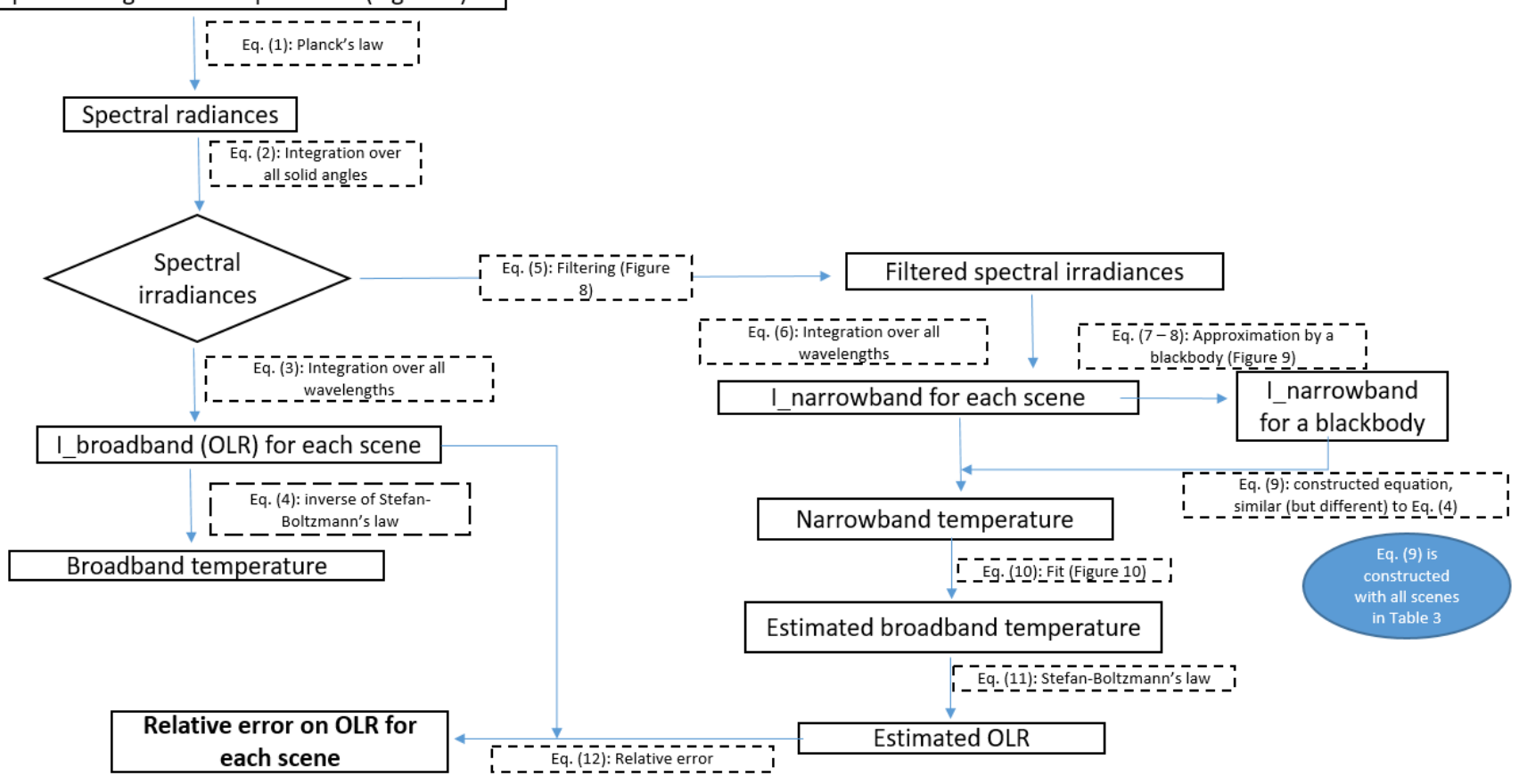

Figure 7. Flowchart summarizing the approach to estimate the Outgoing Longwave Radiation.

\subsection{Simulations of Spectral Brightness Temperatures}

For each of the 15 scenes, the spectral brightness temperatures $T_{\lambda}$ are generated in the wavelength range from $3 \mu \mathrm{m}$ to $100 \mu \mathrm{m}$ (Figure 8). 


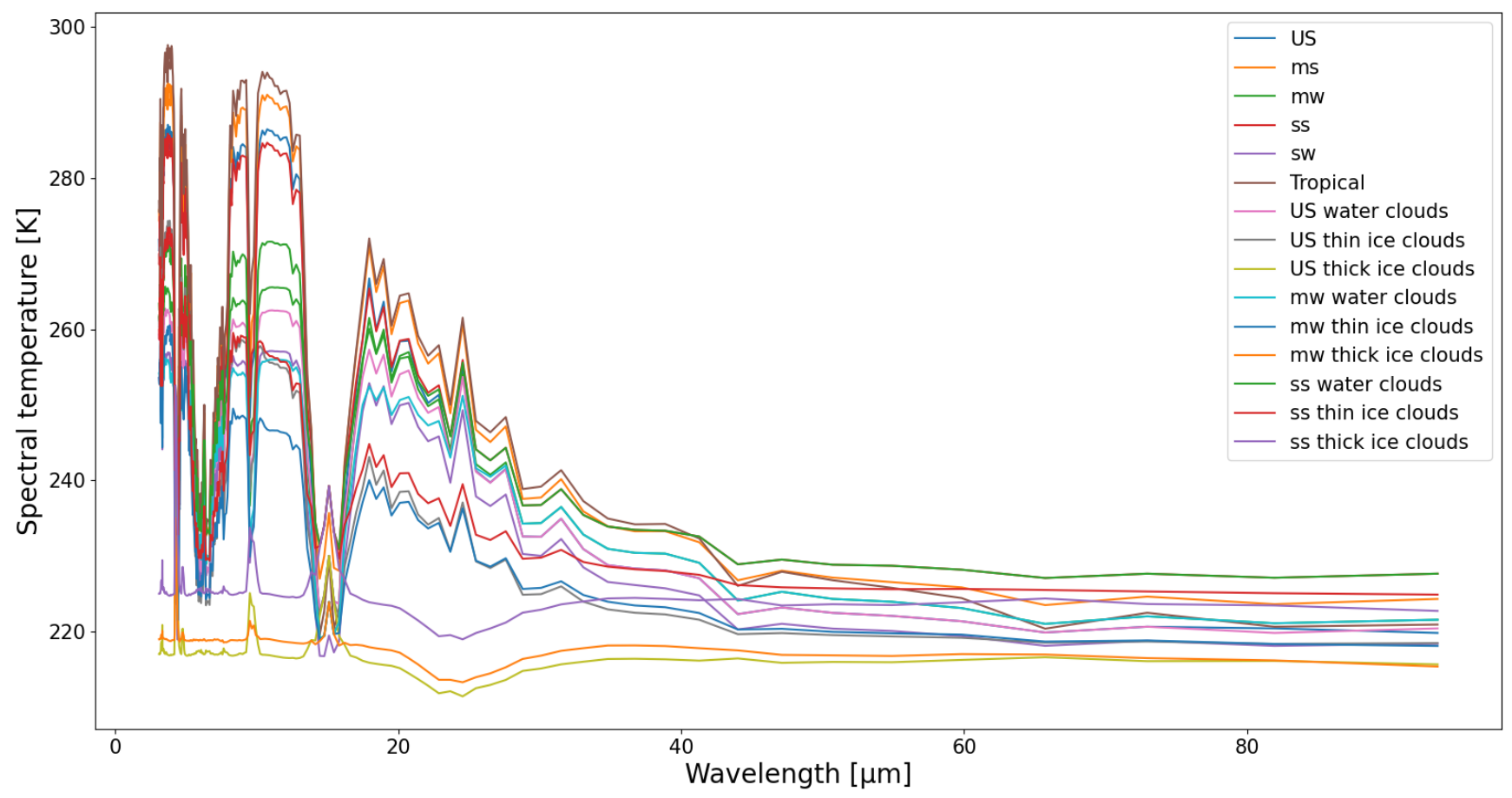

Figure 8. Spectral brightness temperature as function of wavelength for simulated scenes, listed in Table 3.

\subsection{Computation of the Spectral Irradiances}

Each spectral brightness temperature $T_{\lambda}$ (with $\lambda$ the wavelength) is converted into spectral radiances $L(\lambda)$ by using Planck's law [22], in Equation (1), with $h=6.62607015 \times 10^{-34} \mathrm{~J} . \mathrm{s}$ the Planck's constant, $c=299792458 \mathrm{~m} / \mathrm{s}$ the speed of light, and $k=1.380649 \times 10^{-23} \mathrm{~J} / \mathrm{K}$ the Boltzmann's constant. These spectral radiances $L(\lambda)$ are then converted into spectral irradiances $I(\lambda)$ by integration over all solid angles $\Omega$, using Equation (2).

$$
\begin{gathered}
L(\lambda)=\frac{2 h c^{2}}{\lambda^{5}} \frac{1}{\mathrm{e}^{\frac{h c}{\lambda k T_{\lambda}}}-1} \\
I(\lambda)=\int_{\Omega} L(\lambda) d \Omega=\pi L(\lambda)
\end{gathered}
$$

\subsection{Computation of the Broadband Temperatures}

From these spectral irradiances $I(\lambda)$, we can derive the broadband irradiance (the OLR) associated with each scene. By integrating the spectral irradiances over the wavelengths using Equation (3), we obtain the broadband irradiance, from which the broadband temperature $T_{\text {broadband }}$ can be derived, using the inverse of Stefan-Boltzmann's law [22], given by Equation (4).

$$
\begin{gathered}
\text { OLR }=\int_{\lambda} I(\lambda) d \lambda \\
T_{\text {broadband }}=\sqrt[4]{\sigma \text { OLR }}
\end{gathered}
$$

where $\sigma \approx 5.670374 \times 10^{-8} \mathrm{Wm}^{-2} \mathrm{~K}^{-4}$ is the Stefan-Boltzmann's constant.

\subsection{Computation of the Narrowband Temperatures}

For each scene, the narrowband temperature can be computed by applying a similar method to the simulated filtered spectral irradiances, by using Equations (5)-(9). The narrowband irradiance $I_{\text {narrowband }}$ is defined as the integral over the wavelengths of the filtered spectral irradiances $I_{\text {filtered }}(\lambda)$, which are the product of the spectral irradiances by 
the spectral response $\operatorname{SR}(\lambda)$. The spectral response $\operatorname{SR}(\lambda)$ takes into account the transmission of the optical system, i.e., the transmission of the germanium material, and the spectral response of the detector (Figure 9).

$$
\begin{gathered}
I_{\text {filtered }}(\lambda)=\operatorname{SR}(\lambda) I(\lambda) \\
I_{\text {narrowband }}=\int_{\lambda} I_{\text {filtered }}(\lambda) d \lambda
\end{gathered}
$$

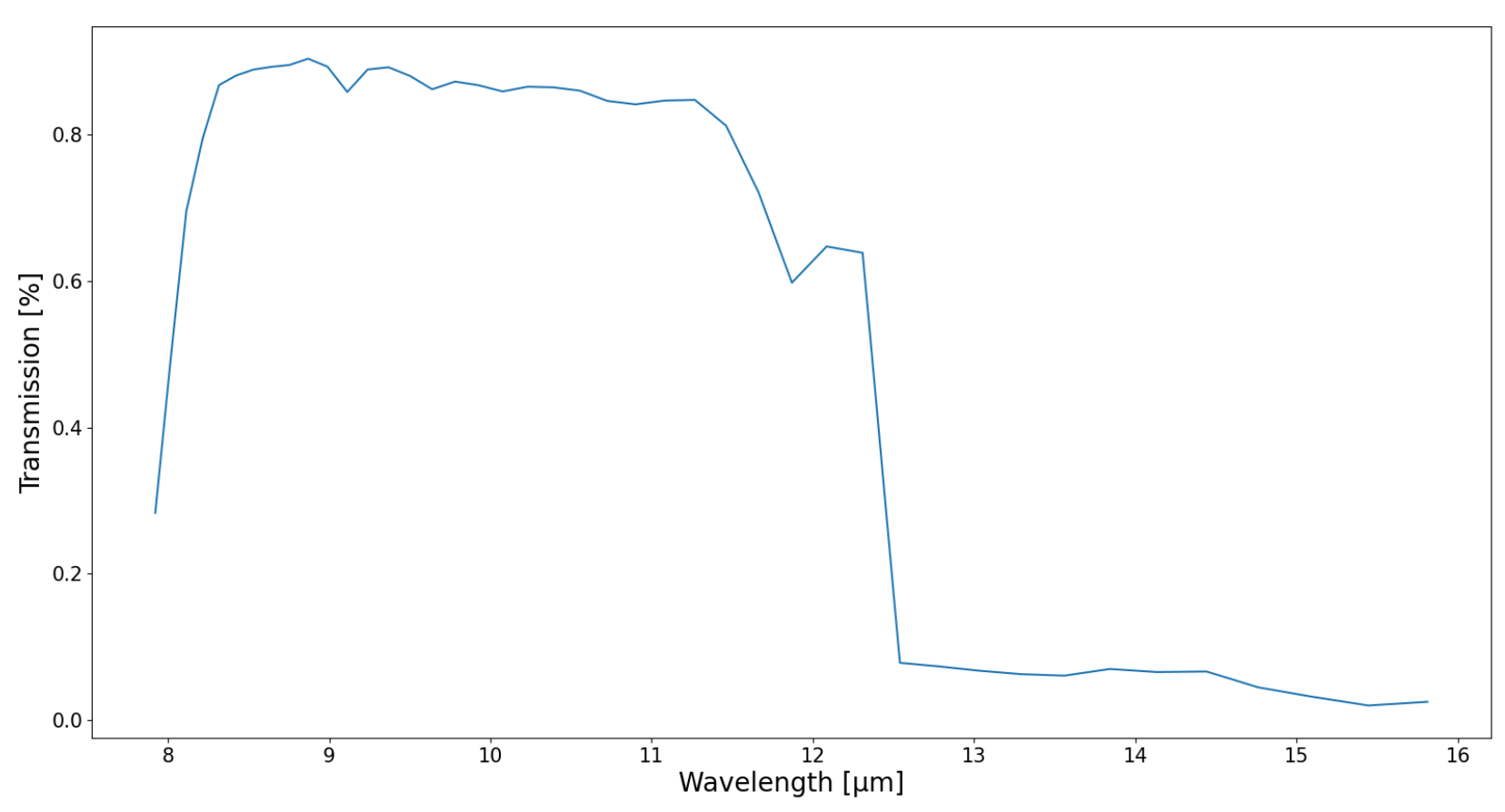

Figure 9. Spectral response of the full optical system, consisting of the germanium lenses and the detector.

Considering a blackbody at temperature $T$, the narrowband irradiance is a function of this temperature.

$$
I_{\text {narrowband }}=I_{\text {narrowband,blackbody }}(T)
$$

$I_{\text {narrowband,blackbody }}(T)$ is illustrated by the blue curve in Figure 10. The analytical fit is illustrated by the orange curve in Figure 10, and is described by Equation (8).

$$
I_{\text {narrowband,blackbody }}(T) \approx(0.00742687 T)^{5.56123}
$$

For an arbitrary scene, the narrowband brightness temperature $T_{\text {narrowband }}$ is defined as the temperature of the equivalent blackbody that results in the same narrowband irradiance $I_{\text {narrowband }}$.

$$
T_{\text {narrowband }}=\frac{I_{\text {narrowband }}^{-5.56123}}{0.00742687}
$$

\subsection{Fit of the Broadband Temperature as Function of the Narrowband Temperature}

Once the broadband temperature $T_{\text {broadband }}$ and the narrowband temperature $T_{\text {narrowband }}$ are obtained for each scene, we plot $T_{\text {broadband }}$ as function of $T_{\text {narrowband }}$ (Figure 11). 


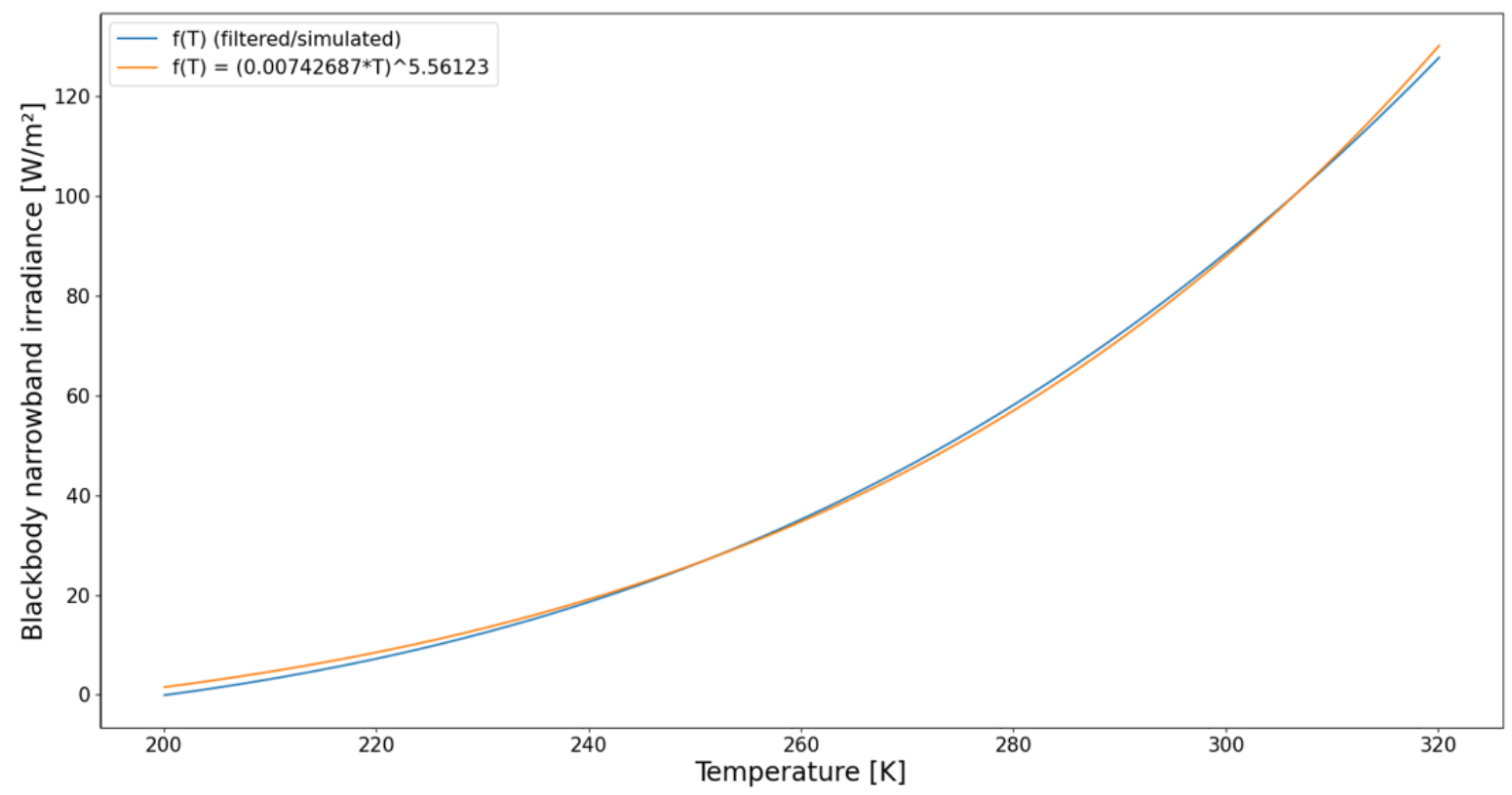

Figure 10. Blackbody narrowband irradiance as function of the blackbody temperature: blue curve $=f(T)$ (filtered/simulated), orange curve = analytical fit.

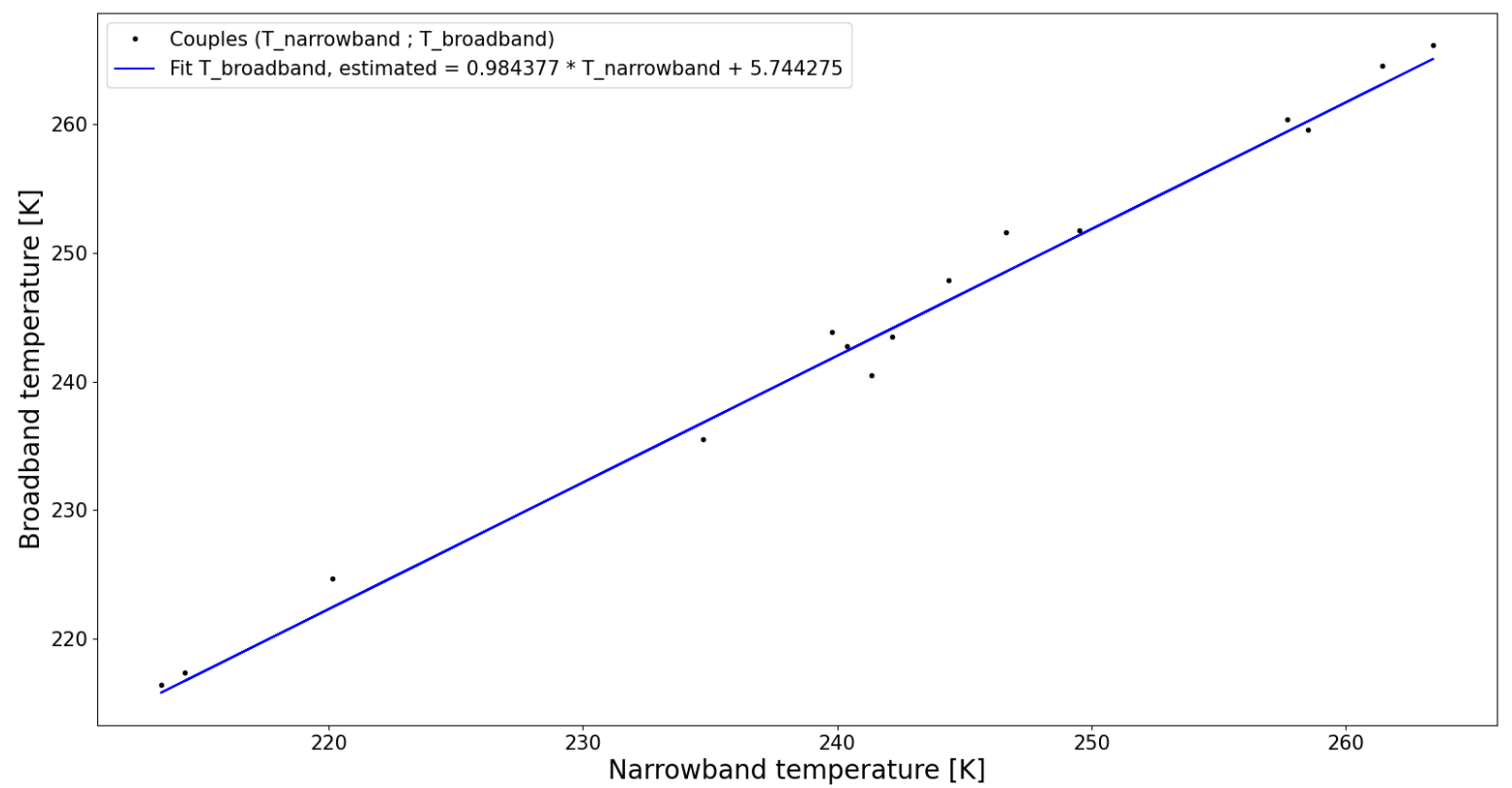

Figure 11. Couples of narrowband temperature and broadband temperature for simulated scenes, listed in Table 3.

Line: linear fit of the broadband temperature as function of the narrowband temperature. $\mathrm{RMSE}=1.498$ and $\mathrm{R}^{2}=0.991$.

Given the simulated narrowband temperature $T_{\text {narrowband, }}$ the broadband temperature can be estimated by

$$
T_{\text {broadband }} \approx T_{\text {broadband,estimated }}=0.984377 \cdot T_{\text {narrowband }}+5.744275
$$

3.6. Estimation of the OLR and Calculation of Error on OLR

The OLR can then be estimated by

$$
\mathrm{OLR} \approx \mathrm{OLR}_{\text {estimated }}=\sigma T_{\text {broadband,estimated }}^{4}
$$


Based on Equations (5), (6), (9)-(11), the OLR is estimated from the narrowband temperature and compared to the theoretical OLR, for each of the simulated scenes that were listed in Table 3.

The relative errors on the OLR estimates are calculated using Equation (12) and are given in the last column of Table 4.

$$
\Delta \mathrm{OLR} / \mathrm{OLR}[\%]=\left(\mathrm{OLR}-\mathrm{OLR}_{\mathrm{estimated}}\right) / \mathrm{OLR}
$$

We conclude that the largest relative error on the OLR equals $4.8 \%$ (Table 4 ), which is within the $5 \%$ requirement that was targeted [8].

Table 4. 15 scenes simulated in libRadtran, listed in Table 3, with their broadband and narrowband temperatures, estimates of the OLR and relative errors on these estimates.

\begin{tabular}{|c|c|c|c|c|}
\hline Scene & $T_{\text {broadband }}[\mathrm{K}]$ & $T_{\text {narrowband }}[\mathrm{K}]$ & OLR $\left[\mathrm{W} / \mathrm{m}^{2}\right]$ & $\frac{\Delta \text { OLR }}{\text { OLR }}[\%]$ \\
\hline U.S. Standard (us) & 258.51 & 259.56 & 260.21 & -1.01 \\
\hline Tropical (tr) & 263.44 & 266.11 & 265.06 & 1.56 \\
\hline Midlatitude Summer (ms) & 261.41 & 264.52 & 263.07 & 2.16 \\
\hline Midlatitude Winter (mw) & 249.53 & 251.73 & 251.37 & 2.16 \\
\hline Subarctic Summer (ss) & 257.70 & 260.34 & 259.42 & 1.41 \\
\hline Subarctic Winter (sw) & 240.38 & 242.71 & 242.36 & 0.57 \\
\hline U.S. Standard with water clouds (us_wc) & 244.39 & 247.86 & 246.31 & 2.47 \\
\hline U.S. Standard with thin ice clouds (us_ic_thin) & 241.33 & 240.46 & 243.30 & -4.80 \\
\hline U.S. Standard with thick ice clouds (us_ic_thick) & 213.40 & 216.41 & 215.81 & 1.10 \\
\hline Midlatitude Winter with water clouds (mw_wc) & 239.79 & 243.81 & 241.79 & 3.28 \\
\hline Midlatitude Winter with thin ice clouds (mw_ic_thin) & 234.73 & 235.49 & 236.81 & 2.25 \\
\hline Midlatitude Winter with thick ice clouds (mw_ic_thick) & 214.35 & 217.35 & 216.75 & 1.10 \\
\hline Subarctic Summer with water clouds (ss_wc) & 246.63 & 251.60 & 248.52 & 4.80 \\
\hline Subarctic Summer with thin ice clouds (ss_ic_thin) & 242.16 & 243.47 & 244.12 & -1.08 \\
\hline Subarctic Summer with thick ice clouds (ss_ic_thick) & 220.15 & 224.67 & 222.46 & 3.89 \\
\hline
\end{tabular}

\section{Discussion}

In order to make a better assessment of the radiative energy fluxes at the top-ofatmosphere, we develop a suite of wide-field-of-view space-based instruments. In addition to the previously published radiometer [8] and shortwave camera [12], providing for the monitoring of the Earth's total outgoing radiation and Reflected Solar Radiation respectively, in this paper we present the design of a longwave camera to monitor the Outgoing Longwave Radiation. The shortwave and longwave cameras are intended to complement each other by observing the spatial distribution of the reflected radiation and emitted thermal radiation, respectively. Both cameras are featuring the same field of view of $140^{\circ}$ and a spatial resolution of minimally $5 \mathrm{~km}$, but the longwave camera is optimized for use in the thermal wavelength range covering 8 to $14 \mu \mathrm{m}$. Despite the fact that the shortwave and longwave camera target similar specifications, the shift towards the thermal wavelength range requires however a full redesign of the camera system due to the use of other lens materials, and the wavelength dependency of the focal length and chromatic lens aberrations.

We target a space mission in the so-called morning orbit, providing continuity after the end of life of the Terra mission, which carries the CERES instrument in the morning orbit. Together with the Libera mission that is going to follow the Aqua mission in the afternoon orbit [6], our targeted space mission will provide for a better sampling of the diurnal cycle. To reduce the cost and time of our satellite, we will make use of a $6 \mathrm{U}$ CubeSat platform, where $1 \mathrm{U}$ will be allocated to our longwave camera.

We assessed the ability to estimate the Outgoing Longwave Radiation from the camera spectral measurements using radiative transfer simulations. As for any simulation of course, all radiative transfer equation (RTE) solvers involve some approximations. Therefore, solutions provided by libRadtran have some uncertainties that are relative to the solution 
method, especially in the longwave regime [23]. However, we use the DISORT solver, which is one of the most common and accurate RTE solvers of libRadtran, as it is suited for most applications. This has been validated in many international model intercomparison studies for radiance calculations [24], giving confidence in the results generated by this model. Consequently, the spectral brightness temperatures, radiances and irradiances have been simulated for different reference scenes using libRadtran [20]. We derived the narrowband and broadband temperatures for each scene, followed by an estimation of the broadband radiation and quantification of the uncertainty on our estimates. According to these radiative transfer simulations, the estimated stand-alone accuracy of the Outgoing Longwave Radiation estimate from the longwave camera equals $4.8 \%$, which is within the $5 \%$ requirement.

Our longwave camera design consists of three germanium singlet lenses. The full field of view equals $140^{\circ}$, enabling to observe the Earth from limb to limb. The targeted spatial resolution of $5 \mathrm{~km}$ at nadir is clearly reached since our spot diagram indicated RMS spot radii smaller than the Airy disk for all wavelengths and all fields. Using $768 \times 768$ pixels with a size of $17 \mu \mathrm{m}$ of the ULIS/Lynred Pico1024Gen2 detector, we find a nominal spatial resolution of $4.455 \mathrm{~km}$ at nadir, beating the requirement of $5 \mathrm{~km}$. Barrel distortion appears to be the main aberration limiting the spatial resolution. The distortion $f \theta$ is maximal at $70^{\circ}$, where it equals $18.85 \%$. An accurate assessment of the optical performance is obtained by considering the polychromatic diffraction MTF, which is well suited to assess the image quality. The results show that the polychromatic MTF is at least 0.5 for all fields at 15 cycles per $\mathrm{mm}$, ensuring a good performance of the optical design. At all wavelengths and all fields, the optical design is close to diffraction-limited. Consequently, we have achieved a compact and WFOV optical design, providing for a good resolution in the thermal range between 8 and $14 \mu \mathrm{m}$. This wavelength range is relatively broad for a WFOV camera, which is beneficial for the estimation of the broadband radiation that is the Outgoing Longwave Radiation.

Our future work will involve a full tolerancing analysis in view of fabricating a demonstrator and prototype system. The lenses of the optical system will be in-house manufactured using the ultra-precision diamond tooling machine. After the manufacturing of the lenses, each lens surface will first be characterized in the cleanroom using the white light interferometer to evaluate the surface roughness, and a coordinate measurement machine will be used to check the surface shape. Following that, we can mount the design in the laboratory, where it will then be tested and calibrated, in view of the development of a flight model to be integrated on board of a remote sensing satellite for the monitoring of the Earth's radiation budget.

\section{Conclusions}

We propose to monitor the Earth's radiation budget with a suite of compact spacebased instruments, adequate for integration within a nano- or micro-satellite. These instruments are a wide-field-of-view radiometer, a shortwave camera and a longwave camera, of which the latter one is the subject of this paper.

The ray tracing simulations supplemented with the radiative transfer computations reveal that our longwave camera yields a sufficiently good image quality to enable scene identification with a spatial resolution better than $5 \mathrm{~km}$, while featuring broadband estimation of the Outgoing Longwave Radiation with a relative uncertainty of less than $5 \%$, owing to its large bandwidth.

Author Contributions: L.S. (Luca Schifano) has conducted this study, including methodology, formal analysis and investigation. L.S. (Lien Smeesters) and F.B. have ensured the supervision on the optical system design, and S.D. has ensured the supervision on the radiative transfer simulations. S.D. is reponsible for funding acquisition. L.S. (Luca Schifano) has written the original draft. All authors have participated in the review and editing. All authors have read and agree to the published version of the manuscript. 
Funding: This research was funded by the Solar-Terrestrial Center of Excellence (STCE).

Acknowledgments: B-PHOT acknowledges the Vrije Universiteit Brussel's Methusalem foundations as well as the Hercules Programme of the Research Foundation Flanders (FWO).

Conflicts of Interest: The authors declare no conflict of interest.

$\begin{array}{ll}\text { Abbreviations } \\ \text { The following abbreviations are used in this manuscript: } \\ \text { 1U } & \text { 1 CubeSat Unit } \\ \text { ADM } & \text { Angular Distribution Models } \\ \text { CERES } & \text { Clouds and the Earth's Radiant Energy System } \\ \text { COTS } & \text { Commercial Off-The-Shelf } \\ \text { EEI } & \text { Earth's Energy Imbalance } \\ \text { ERB } & \text { Earth's Radiation Budget } \\ \text { FOV } & \text { Field Of View } \\ \text { IMA } & \text { IMAge } \\ \text { LW } & \text { LongWave } \\ \text { MTF } & \text { Modulation Transfer Function } \\ \text { NASA } & \text { National Aeronautics and Space Administration } \\ \text { OBJ } & \text { OBJect } \\ \text { OLR } & \text { Outgoing Longwave Radiation } \\ \text { RMS } & \text { Root Mean Square } \\ \text { RMSE } & \text { Root-Mean-Square Error } \\ \text { RSR } & \text { Reflected Solar Radiation } \\ \text { RTE } & \text { Radiative Transfer Equation } \\ \text { SIMBA } & \text { Sun-earth IMBAlance } \\ \text { SW } & \text { ShortWave } \\ \text { TOA } & \text { Top-Of-Atmosphere } \\ \text { TRMM } & \text { Tropical Rainfall Measuring Mission } \\ \text { WFOV } & \text { Wide-Field-Of-View }\end{array}$

\section{References}

1. Dewitte, S.; Clerbaux, N. Measurement of the Earth Radiation Budget at the Top of the Atmosphere-A Review. Remote Sens. 2017, 9, 1143. [CrossRef]

2. Wielicki, B.A.; Barkstrom, B.R.; Harrison, E.F.; Lee, R.B., III; Smith, G.L.; Cooper, J.E. Clouds and the Earth's Radiant Energy System (CERES): An Earth observing system experiment. BAMS 1996, 77, 853-868. [CrossRef]

3. Loeb, N.G.; Doelling, D.R. Clouds and the earth's radiant energy system (CERES) energy balanced and filled (EBAF) top-ofatmosphere (TOA) edition-4.0 data product. J. Clim. 2018, 31, 895-918. [CrossRef]

4. Loeb, N.; Smith, N.M.; Kato, S.; Miller, W.F.; Gupta, S.K.; Minnis, P.; Wielicki, B. Angular Distribution Models for TOA radiative flux estimation from the CERES instrument on the TRMM satellite. Part 1: Methodology. JAM 2002, 42, $240-265$.

5. Ackerman, S.A.; Holz, R.E.; Frey, R. Cloud Detection with MODIS. Part II: Validation. Am. Meteorol. Soc. 2008, 25, 1073-1086. [CrossRef]

6. Pilewskie. P. Libera and Continuity of the ERB Climate Data Record; American Geophysical Union: Washington, DC, USA, 2020.

7. Earth Venture Continuity Radiation Budget Science Working Group. Measurement and Instrument Requirement Recommendations for an Earth Venture Continuity Earth Radiation Budget Instrument. 2018. Available online: https://smdprod.s3.amazonaws.com/science-pink/s3fs-public/atoms/files/ERB_SWG_Rept_Draft_07242018_TAGGED.pdf (accessed on 14 May 2020).

8. Schifano, L.; Smeesters, L.; Geernaert, T.; Berghmans, F.; Dewitte, S. Design and analysis of a next generation wide field-of-view Earth Radiation Budget radiometer. Remote Sens. 2020, 12, 425. [CrossRef]

9. Hansen, J.; Sato, M.; Kharecha, P.; von Schuckmann, K. Earth's energy imbalance and implications. Atmos. Chem. Phys. 2011, 11, 13421-13449. [CrossRef]

10. Trenberth, K.E.; Fasullo, J.T.; von Schuckmann, K.; Cheng, L. Insights into Earth's Energy Imbalance from Multiple Sources. J. Clim. 2016, 29, 7495-7505. [CrossRef]

11. von Schuckmann, K.; Palmer, M.D.; Trenberth, K.E.; Cazenave, A.; Chambers, D.; Champollion, N.; Hansen, J.; Josey, S.A.; Loeb, N.; Mathieu, P.-P.; et al. An imperative to monitor Earth's energy imbalance. Nat. Clim Chang. 2016, 6, 138-144. [CrossRef]

12. Schifano, L.; Smeesters, L.; Berghmans, F.; Dewitte, S. Optical system design of a wide field-of-view camera for the characterization of earth's reflected solar radiation. Remote Sens. 2020, 12, 2556. [CrossRef] 
13. Del Pozo, S.; Sáez Blázquez, C.; Martín Nieto, I.; Lagüela, S. Integrated Approach for Detecting Convection Effects in Geothermal Environments Based on TIR Camera Measurements. Appl. Sci. 2021, 11, 3185. [CrossRef]

14. Qiu, R.; Dou, W.; Kan, J.; Yu, K. Optical design of wide-angle lens for LWIR earth sensors. In Proceedings of the SPIE 10209, Image Sensing Technologies: Materials, Devices, Systems, and Applications IV, Anaheim, CA, USA, 12-13 April 2017; p. 102090T.

15. Zhu, C.; Hobbs, M.J.; Grainger, M.P.; Willmott, J.R. Design and realization of a wide field of view infrared scanning system with an integrated micro-electromechanical system mirror. Appl. Opt. 2018, 57, 10449-10457. [CrossRef] [PubMed]

16. Infante Herrero, J.M.; Muñoz, F.; Benitez, P.; Miñano, J.C.; Wang, L.; Vilaplana, J.; Biot, G.; de La Fuente, M. Novel fast catadioptric objective with wide field of view. In Proceedings of the SPIE 7787, Novel Optical Systems Design and Optimization XIII, San Diego, CA, USA, 27 August 2010; p. 778704.

17. SCHOTT $^{\circledR}$ Website. Available online: https://www.schott.com/ (accessed on 12 May 2020).

18. Normanshire, C. Designing for As-Built Performance with High-Yield Optimization; MyZemax: Seattle, WA, USA, 2020 ; KA-01837.

19. Riedl, M.J. Seidel and the Pegel Diagrams. In Optical Design: Applying the Fundamentals; SPIE Press: Bellingham, WA, USA, 2009.

20. Mayer, B.; Emde, C.; Buras-Schnell, R., Kylling, A. Radiative transfer: Methods and applications. In Atmospheric Physics; Springer: Berlin/Heidelberg, Germany, 2012; pp. 401-415.

21. Anderson, G.; Clough, S.; Kneizys, F.; Chetwynd, J.; Shettle, E. AFGL Atmospheric Constituent Profiles (0-120 km); Tech. Rep. AFGL-TR-86-0110; Air Force Geophysics Laboratory, Air Force Systems Command, United States Air Force: Hanscom AFB, MA, USA, 1986; p. 10294.

22. Kittel, C.; Kroemer, H. Thermal Physics; W.H. Freeman and Company: New York, NY, USA, 1980.

23. Mayer, B.; Kylling, A.; Emde, C.; Buras, R.; Hamann, U.; Gasteiger, J.; Richter, B. libRadtran User's Guide. 2020. Available online: http:/ / www.libradtran.org/doc/libRadtran.pdf (accessed on 2 February 2021 ).

24. Emde, C.; Buras-Schnell, R.; Kylling, A.; Mayer, B.; Gasteiger, J.; Hamann, U.; Kylling, J.; Richter, B.; Pause, C.; Dowling, T.; Bugliaro, L. The libRadtran software package for radiative transfer calculations (version 2.0.1). Geosci. Model Dev. 2016, 9, 1647-1672. [CrossRef] 